\title{
Pendidikan Kesehatan Menggunakan Booklet Terhadap Pemahaman Pasien Hipertensi Di Puskesmas
}

\author{
Wijayanti $^{1}$, Budhi Mulyadi ${ }^{2}$ \\ ${ }^{1.2}$ Program S1 Keperawatan STIKIM Jakarta \\ Sekolah Tinggi Ilmu Kesehatan Indonesia Maju Jakarta \\ Jln. Harapan Nomor. 50, Lenteng Agung- Jakarta Selatan 12610 \\ Telp: (021) 78894045 Email: ${ }^{1} w i j a y a n t i @ g m a i l . c o m,{ }^{2}$ budhimulyadi@gmail.com.
}

\begin{abstract}
Abstrak
Hipertensi merupakan salah satu penyebab morbiditas dan mortalitas paling sering di seluruh dunia. Keberhasilan pendidikan kesehatan kepada masyarakat dipengaruhi oleh media dan metode yang tepat yaitu booklet, karena booklet memberikan informasi dengan spesifik, dan banyak digunakan sebagai media alternative untuk dipelajari setiap saat bila seseorang menghendakinya. Tujuan penelitian ini yaitu mengetahui pengaruh pendidikan melalui pemberian booklet dan penyuluhan tentang penyakit hipertensi dengan pengetahuan pasien hipertensi di Puskesmas Bogor Tengah. Desain penelitian ini quasyeks perimen. Populasi pada penelitian ini sebesar 33 orang dan sampel pada penelitian ini menggunakan total populasi yaitu sebesar 33 orang. Alat pengumpulan data menggunakan kuesioner. Hasil penelitian menunjukkan bahwa sebelum diberi booklet pasien yang memiliki pemahaman rendah dan .sesudah diberi booklet pasien yang memilki pemahaman tinggi. Hasil uji statistic dengan menggunakan uji t paired sampel $\mathrm{t}$ - test didapatkan ada pengaruh pendidikan kesehatan dengan menggunakan booklet terhadap pemahaman pasien hipertensi di Puskesmas Kecamatan Pasar Minggu Tahun 2016. Untuk meningkatkan pengetahuan pasien maka penting untuk menambah media pendidikan kesehatan diwilayah Puskesmas Bogor Tengah.
\end{abstract}

Kata Kunci $\quad$ : Pendidikan Kesehatan, Booklet, Hipertensi

\begin{abstract}
Hypertension is one of the causes of morbidity and mortality of the most frequently worldwide. The success of health education to the public and the media are influenced by appropriate methods, namely booklets, because booklet provides specific information, and is widely used as an alternative medium to be studied at any time when someone wills. The purpose of this research is to know the influence of education through the provision of booklets and education about hypertension with knowledge of patients with hypertension in the Health Center of Central Bogor. Quasy experimental design of this study. The population in this study amounted to 33 people and sample in this study using a total population of 33 people. Tool data collection using questionnaires. The results showed that before being given a booklet of patients who have a low understanding and sesudah given a booklet of patients who have a high understanding. The results of statistical tests using paired t test sample $t$ - test found no effect of health education using booklet on hypertension in the patient's understanding of District Health Clinics PasarMinggu Year 2016. To increase knowledge of the patient it is important to increase health education media in the region of Central Bogor health center.
\end{abstract}

Keywords $\quad$ : Health Education, Booklet, Hypertension 


\section{Pendahuluan}

Tekanan darah tinggi atau hipertensi adalah kondisi medis di mana terjadi peningkatan tekanan darah secara kronis (dalam jangka waktu lama). Penderita yang mempunyai sekurang-kurangnya tiga bacaan tekanan darah yang melebihi $140 / 90 \mathrm{mmHg}$ saat istirahat diperkirakan mempunyai keadaan darah tinggi. ${ }^{1}$

Hipertensi menjadi momok bagi sebagian besar penduduk dunia termasuk Indonesia. Hal ini karena secara statistik jumlah penderita yang terus meningkat dari waktu ke waktu. Berbagai faktor yang berperan dalam hal ini salah satunya adalah gaya hidup modern. Pemilihan makanan yang berlemak, kebiasaan aktifitas yang tidak sehat, merokok, minum kopi serta gaya hidup sedetarian adalah beberapa hal yang disinyalir sebagai faktor yang berperan terhadap hipertensi ini. Penyakit ini dapat menjadi akibat dari gaya hidup modern serta dapat juga sebagai penyebab berbagai penyakit non infeksi. Hal ini berarti juga menjadi indikator bergesernya dari penyakit infeksi menuju penyakit non infeksi, yang terlihat dari urutan penyebab kematian di Indonesia Hipertensi menyebabkan meningkatnya resiko terhadap stroke, aneurisma, gagal jantung, serangan jantung dan kerusakan ginjal. Tanpa melihat usia atau jenis kelamin, semua orang bisa terkena hipertensi dan biasanya tanpa ada gejala-gejala sebelumnya. Hipertensi juga dapat mengakibatkan kerusakan berbagai organ target seperti otak, jantung, ginjal, aorta, pembuluh darah perifer dan retina. Oleh karena itu, negara Indonesia yang sedang membangun di segala bidang perlu memperhatikan pendidikan kesehatan masyarakat untuk mencegah timbulnya penyakit seperti hipertensi, kardiovaskuler, penyakit degeneratif dan lain-lain, sehingga potensi bangsa dapat lebih dimanfaatkan untuk proses pembangunan. Golongan umur 45 tahun ke atas memerlukan tindakan atau program pencegahan yang terarah. Hipertensi perlu dideteksi dini yaitu dengan pemeriksaan tekanan darah secara berkala, yang dapat dilakukan pada waktu check-up kesehatan atau saat periksa ke dokter. ${ }^{2}$

Badan Kesehatan Dunia WHO tahun 2011 mencatat, satu milyar orang di dunia menderita hipertensi dan dua per tiga diantaranya berada di Negara-negara berkembang yang berpenghasilan rendah sedang. Oleh karena itu hipertensi merupakan masalah kesehatan dunia yang mencemaskan dan menyebabkan beban biaya kesehatan yang tinggi. Prevalensi hipertensi akan terus meningkat dan diprediksi pada tahun 2025 sebanyak $29 \%$ orang dewasa di seluruh dunia terkena hipertensi. Dalam Statistik Kesehatan Dunia tahun 2012 WHO melaporkan bahwa hipertensi adalah suatu kondisi beresiko tinggi yang menyebabkan sekitar $51 \%$ dari kematian akibat stroke dan $45 \%$ dari penyakit jantung koroner. ${ }^{3}$

Prevalensi hipertensi di Indonesia sebesar $31,7 \%$ yang berarti 1 dari 3 orang mengalami hipertensi dan sebanyak $76,1 \%$ tidak mengetahui dirinya telah mengalami hipertensi sehingga tidak mendapatkan pengobatan hipertensi. ${ }^{4}$ Padahal hipertensi yang tidak diobati dapat menyebabkan komplikasi yang fatal seperti, serangan jantung, stroke, dan gagal ginjal. Hipertensi juga dapat menyebabkan kebutaan, irama jantung tak beraturan dan gagal jantung. Pencegahan penyakit hipertensi dapat dimulai dari pasien itu sendiri. Pasien hipertensi harus mampu mengetahui cara merawat dan mengontrol penyakitnya. Pengetahuan itu sendiri dipengaruhi oleh faktor pendidikan formal. Pengetahuan sangat erat hubungannya dengan pendidikan, dimana diharapkan bahwa dengan pendidikan yang luas maka orang tersebut akan semakin luas pula pengetahuannya. ${ }^{5}$

Dalam rangka meningkatkan pemahaman masyarakat tentang bagaimana cara penanganan penyakit hipertensi yang benar adalah dengan cara memberikan pendidikan kesehatan kepada masyarakat terutama pasien hipertensi, sehingga diharapkan dapat menurunkan angka kejadian hipertensi dan komplikasi akibat hipertensi. Materi pendidikan kesehatan yang perlu diberikan meliputi bagaimana pencegahan dan pengobatan penyakit hipertensi. Pendidikan kesehatan adalah upaya untuk mempengaruhi orang lain, baik individu, kelompok, atau masyarakat, agar melaksanakan perilaku hidup sehat. Sedangkan secara operasional, pendidikan kesehatan merupakan suatu kegiatan untuk memberikan dan atau meningkatkan pengetahuan, sikap, dan praktek masyarakat dalam memelihara dan meningkatkan kesehatan mereka sendiri. ${ }^{6}$ 
Pendidikan kesehatan merupakan bagian dari keseluruhan upaya kesehatan (promotif, preventif, kuratif dan rehabilitatif) yang menitikberatkan pada upaya untuk meningkatkan perilaku hidup sehat. Pendidikan kesehatan dapat diperoleh melalui media promosi kesehatan. Berbagai macam jenis media promosi kesehatan yang dapat dimanfaatkan misalnya poster, leaflet, booklet maupun film dalam bentuk VCD. Menurut Laporan Tahunan Puskesmas Kecamatan Pasar Minggu Tahun 2016, hipertensi merupakan penyakit terbanyak di Puskesmas Kecamatan Pasar Minggu dengan kasus kunjungan 5043 pengunjung. Hasil studi pendahuluan yang dilakukan peneliti yaitu promosi kesehatan di Puskesmas Kecamatan Pasar Minggu sudah berjalan tetapi belum optimal, karena belum mendapatkan perhatian khusus terutama pada aspek pencegahan dan promosinya. Kesediaan media baik leaflet, poster, maupun VCD untuk berbagai jenis program kesehatan sudah ada, tetapi media promosi kesehatan khusus untuk hipertensi tidak lengkap seperti hanya terdapat leaflet lama yang tidak pernah di update, sehingga petugas kesehatan merasa bosan dengan penyampaian materi menggunakan alat hanya dengan itu-itu saja. Peran ganda yang dirasakan juga menjadi permasalahan seperti pekerjaan yang double karena kurangnya orang atau karena teman yang tidak masuk. Salah satu faktor yang menyebabkan ketidaktahuan dan kurang baiknya sikap pasien dalam penanganan penyakit hipertensi karena kurang optimalnya pemberian pendidikan kesehatan kepada masyarakat. Pada kasus diatas, salah satu sikap pasien yang kurang mendukung antara lain karena pasien menganggap penyakit hipertensi merupakan penyakit yang biasa. Oleh sebab itu perlu ada usaha promosi kesehatan melalui media khusus hipertensi sehingga pengetahuan pasien hipertensi menjadi baik dan tentunya akan berdampak langsung pada penurunan kasus hipertensi di Puskesmas Kecamatan Pasar Minggu khususnya.

Berdasarkan latar belakang diatas, yaitu tentang pentingnya pendidikan kesehatan dalam merubah sikap pasien maka peneliti bermaksud melakukan penelitian tentang pengaruh pendidikan kesehatan menggunakan booklet terhadap pemahaman pasien hipertensi di Puskesmas Kecamatan Pasar Minggu Tahun 2016. Tujuan umum tujuan umum penelitian ini adalah mengetahui pengaruh pendidikan kesehatan menggunakan booklet terhadap pemahaman pasien hipertensi di Puskesmas Kecamatan Pasar Minggu Tahun 2016.

\section{Metode}

Desain Penelitian ini adalah penelitian kuasi eksperimen (quasi experimental) dengan rancangan non-randomized pre-test-post-test group design. ${ }^{5}$ Penelitian eksperimen merupakan penelitian yang dilakukan dengan melakukan manipulasi yang bertujuan untuk mengetahui akibat manipulasi terhadap perilaku individu yang diamati. Manipulasi yang dilakukan dapat berupa situasi atau tindakan tertentu yang diberikan kepada individu atau kelompok dan setelah itu dilihat pengaruhnya. Eksperimen ini dilakukan untuk mengetahui efek yang ditimbulkan dari suatu perlakuan yang diberikan secara sengaja oleh peneliti. $^{7}$

Dalam populasi studi, kriteria yang digunakan adalah pasien yang memiliki riwayat hipertensi yang berobat di Puskesmas Kecamatan Pasar Minggu. Kriteria tersebut dipilih karena peneliti menganggap pasien tersebut memiliki kesempatan untuk dilakukan pemberdayaan terhadap pasien hipertensi. Sehingga populasi studi dari penelitian ini adalah 33 orang.

Pengambilan sampel dalam penelitian ini menggunakan penelitian populasi atau sampel total dimana penelitian populasi hanya dapat dilakukan bagi populasi terhingga atau subjeknya tidak terlalu banyak yaitu sebanyak 33 pasien. ${ }^{8}$

Maka penulis mengambil sampling sesuai dengan teknik total sampling atau penelitian populasi karena subjeknya meliputi semua yang terdapat di dalam populasi maka jumlah sampel yang diambil yaitu seluruh populasi sebanyak 33 pasien. ${ }^{8}$

Adapun teknik pengumpulan data yang digunakan pada penelitian ini adalah menggunakan kuesioner. Responden diminta untuk membaca dengan teliti, kuesioner yang diberikan dan menjawab dengan tanda ceklist $(\sqrt{ })$ pada pilihan yang sesuai menurut responden. Jenis data yang akan diambil adalah data primer yang diperoleh dengan pengambilan data dari pasien langsung, instrument dalam penelitian adalah kuesioner akan dibuat sendiri yang merupakan sejumlah pertanyaan tertulis dan akan dibaca serta dijawab oleh responden penelitian. Cara menyusun sebuah kuesioner penelitian adalah kuesioner penelitian disusun berpedoman pada 
kerangka konsep/kerja penelitian kemudian pertanyaan dalam kuesioner disusun berdasarkan variabel penelitian yang telah diturunkan ke dalam definisi operasional lalu tetapkan skala pengukuran data dari setiap jawaban kuesioner. Sebaiknya gunakan satu skala pengukuran untuk satu variabel agar mempermudah dalam menganalisis data, selain menggunakan kuesioner peneliti juga akan menggunakan catatan rekam medik pasien. Peneliti akan melakukan pretest terhadap pasien hipertensi lalu dinilai hasil pretest tersebut setelah itu pasien diberikan pendidikan kesehatan menggunakan booklet.

Tujuan dari analisa univariat adalah untuk menjelaskan karakteristik masingmasing variabel yang diteliti, dalam penelitian ini yaitu tanda dan gejala hipertensi. Uji tersebut digunakan untuk mengetahui pengaruh sebelum dan sesudah diberikan pendidikan kesehatan terhadap pemahaman pasien hipertensi. Interpretasi dari uji paired $t$ test yaitu dengan menggunakan taraf signifikan $(\alpha=0,05)$.

\section{Hasil}

\section{Analisis Univariat}

Berdasarkan tabel 1 di bawah menunjukan usia responden dalam pendidikan kesehatan menggunakan booklet terhadap pemahaman pasien hioertensi di Puskesmas Kecamatan Pasar Minggu sebagian besar $>30$ tahun $(60,6 \%)$.

Tabel 1 di atas menunjukan jenis kelamin responden dalam pendidikan kesehatan menggunakan booklet terhadap pemahaman pasien hioertensi di Puskesmas Kecamatan Pasar Minggu sebagian besar lakilaki (75,8\%).

Berdasarkan tabel 1 menunjukan pendidikan responden dalam pendidikan kesehatan menggunakan booklet terhadap pemahaman pasien hioertensi di Puskesmas Kecamatan Pasar Minggu sebagian besar tidak sekolah $(33,3 \%)$.

Tabel diatas menunjukan distribusi frekuensi pemahaman pasien sebelum pemberian pendidikan kesehatan menggunakan booklet di Puskesmas Kecamatan Pasar Minggu sebagian besar rendah (60,6\%). Tabel diatas menunjukan distribusi frekuensi pemahaman pasien sesudah pemberian pendidikan kesehatan menggunakan booklet di Puskesmas Kecamatan Pasar Minggu sebagian besar tinggi $(69,7 \%)$.

Tabel 1. Presentase usia, jenis kelamin, pendidikan dan pemahaman pasien hipertensi sebelim dan sesudah diberikan pendidikan kesehatan menggunakan booklet terhadap pemahaman pasien hipertensi di Puskesmas Kecamatan Pasar Minggu Tahun $2016(\mathrm{n}=33)$

\begin{tabular}{lcc}
\hline \multicolumn{1}{c}{ Variabel } & (n) & (f) \\
\hline Usia & & \\
$\quad$ < 30 Tahun & 13 & 39,4 \\
$\quad$ 30 Tahun & 20 & 60,6 \\
Jenis kelamin & & \\
$\quad$ Laki-laki & 25 & 75,8 \\
$\quad$ Perempuan & 8 & 24,2 \\
Pendidikan & & \\
$\quad$ Tidak Sekolah & 11 & 33,3 \\
$\quad$ SD & 5 & 15,2 \\
$\quad$ SMP & 7 & 21,2 \\
$\quad$ SMA & 6 & 18,2 \\
$\quad$ D III & 4 & 12,1 \\
Pemahaman Pasien Hipertensi & & \\
(Sebelum) & & \\
$\quad$ Tinggi & 13 & 39,4 \\
$\quad$ Rendah & 20 & 60,6 \\
Pemahaman Pasien Hipertensi & & \\
(Sesudah) & & \\
$\quad$ Tinggi & 23 & 69,7 \\
$\quad$ Rendah & 10 & 30,3 \\
\hline Sumber : Sistem Komputerisasi 2016 & &
\end{tabular}

\section{Uji Paired Sample T-test}

Table 2. Pengaruh Pendidikan Kesehatan Menggunakan Booklet Terhadap Pemahaman Pasien Hipertensi Di Puskesmas Kecamatan Pasar Minggu Tahun $2016(\mathrm{n}=30)$

\begin{tabular}{ccccc}
\hline Variabel & Mean & SD & SE & P value \\
\hline Sebelum diberi booklet & 7.15 & 1.623 & .282 & \\
Sesudah diberi booklet & 17.70 & 2.433 & .425 & .000 \\
\hline Sumber : Sistem Komputerisasi 2016 & & &
\end{tabular}


Berdasarkan Tabel 2 rata-rata skor pemahaman pasien sebelum diberi pendidikan kesehatan menggunakan booklet adalah 7,15 dengan standard deviasi 1.623 dan standard eror .282. sesudah diberi pendidikan kesehatan menggunakan booklet didapatkan rata-rata skor pemahan adalah 17.70 dengan standard deviasi 2.433 dan standard eror .425. Hasil uji statistic dengan menggunakan paired sample $t$ test didapatkan $p$ value $.000(\mathrm{p}<0,05)$, maka Ho di tolak dan ada pengaruh pendidikan kesehatan menggunakan booklet terhadap pemahaman pasien hipertensi di Puskesmas Kecamatan Pasar Minggu Tahun 2016.

\section{Pembahasan}

Hasil penelitian pengaruh pendidikan kesehatan melalui booklet terhadap pengetahuan pasien hipertensi di wilayah Puskesmas Kecamatan Pasar Minggu dengan menggunakan uji statistik paired-sample t test. Hasil analisis menunjukkan bahwa:

\section{Berdasarkan variabel frekuensi pemahaman pasien sebelum pemberian pendidikan kesehatan menggunakan booklet}

Hasil Penelitian menunjukkan distribusi frekuensi pemahaman pasien sebelum pemberian pendidikan kesehatan menggunakan booklet di Puskesmas Pasar Minggu sebagian besar rendah $(60,6 \%)$.

Hasil penelitian yang dilakukan oleh Ade Ayu Yuliani, dengan judul penelitian efektivitas pendidikan kesehatan reproduksi tentang seks bebas terhadap peningkatan pengetahuan remaja kelas 2 di SMK Islam Wijaya Kusuma Jakarta Selatan. Desain penelitian yaitu pra-eksperimen dengan rancangan one group pretest-postest, dengan total sampling sebanyak 160 siswa. Hasil penelitian menunjukkan bahwa ada hubungan keefektifan pendidikan kesehatan reproduksi tentang seks bebas terhadap peningkatan pengetahuan remaja $(\mathrm{p}<0.05) .{ }^{11}$

Menurut Maulana, bahwa pengetahuan merupakan hasil dari tahu, yang terjadi setelah orang melakukan penginderaan terhadap objek tertentu. Sebagian besar pengetahuan diperoleh melalui mata dan telinga. Pengetahuan merupakan pedoman dalam membentuk tindakan seseorang (overt behaviour). Berdasarkan pengalaman dan penelitian, diperoleh bahwa perilaku yang didasari oleh pengetahuan lebih langgeng daripada perilaku yang tidak disadari pengetahuan. ${ }^{12}$

Menurut Mahmudi, pelaksanaan pendidikan kesehatan merupakan hubungan antara output dengan tujuan, semakin besar kontribusi output terhadap pencapaian tujuan maka semakin efektif organisasi, program, atau kegiatan. Sehubungan dengan hal tersebut, maka pelaksanaan pendidikan kesehatan mengacu pada hasil guna dari pendidikan kesehatan yang menyatakan sejauh mana tujuan telah dicapai, serta ukuran berhasil tidaknya pelaksanaan pendidikan kesehatan mencapai tujuan dan targetnya. ${ }^{13}$

Menurut peneliti, sesuai dengan hasil penelitian di lapangan perawat telah melakukan tugasnya untuk memberikan pendidikan kesehatan kepada pasien. Namun setelah peneliti melakukan observasi di lapangan banyak perawat yang memberikan pendidikan kesehatan tanpa memperhatikan evaluasi dari pendidikan kesehatan itu sendiri, banyak pasien tidak fokus dalam mengikuti pendidikan kesehatan sehingga tidak efektif dalam menerima pengetahuan, seharusnya perawat lebih meningkatkan kemampuannya kembali dalam melakukan pendidikan kesehatan khusunya menggunakan booklet.

\section{Berdasarkan variabel frekuensi pemahaman pasien sesudah pemberian pendidikan kesehatan menggunakan booklet}

Hasil penelitian menunjukkan distribusi frekuensi pemahaman pasien sesudah pemberian pendidikan kesehatan menggunakan booklet di Puskesmas Pasar Minggu sebagian besar tinggi $(69,7 \%)$.

Hasil penelitian ini sejalan dengan penelitian oleh Mustofa, yang berjudul "Hubungan pengetahuan dengan perilaku penderita hipertensi dalam pencegahan stroke" yang menyatakan bahwa $58 \%$ memiliki pengetahuan tinggi.

Menurut Notoatmodjo S, pengetahuan (knowledge) adalah hasil dari tahu dari manusia yang sekedar menjawab pertanyaan "what". Pengetahuan merupakan hasil dari tahu dan ini terjadi setelah orang melakukan penginderaan terhadap suatu objek tertentu. Pengetahuan manusia diperoleh melalui mata dan telinga. Pengetahuan yang diperoleh seseorang sangat dipengaruhi oleh berbagai sumber informasi yang didapatkan baik internet, surat kabar, tabloid atau majalah, 
radio, TV, pendidikan kesehatan, bahkan dari orang lain. ${ }^{5}$

Menurut Hendra. salah satu faktor yang mempengaruhi pengetahuan adalah informasi. Meskipun seseorang memiliki pendidikan yang rendah tetapi jika ia mendapatkan informasi yang baik dari berbagai media misalnya TV, radio, surat kabar, dan pendidikan kesehatan dapat meningkatkan pengetahuan seseorang. ${ }^{14}$

Pengetahuan merupakan salah satu hal penting bagi keluarga dalam mencegah kekambuhan pasien. Hasil penelitian di atas menunjukkan bahwa pemahaman keluarga tentang pencegahan kekambuhan pada pasien isolasi sosial kurang baik, hal ini terjadi karena sumber informasi yang didapat hanya melalui pendidikan kesehatan saja tanpa mencari dari sumber informasi yang lain seperti dari internet, majalah, surat kabar, serta kurang sosialisasi dengan orang lain dan pendidikan kesehatan yang diberikan oleh perawat juga kurang efektif. ${ }^{15}$

Menurut peneliti, dengan pemberian pendidikan kesehatan menggunakan booklet lebih efektif disbanding perawat memberikan pendidikan kesehatan hanya dengan kemampuan bicaranya sesuai dengan pengetahuan yang didapatkan. Pemberian pendidikan kesehatan dengan booklet lebih menarik dan lebih memfokuskan pada pasien, sehingga apa yang disampaikan mudah diterima oleh pasien, oleh karena itu perawat harus meningkatkan kemampuan dan ilmu pengetahuan dengan mengikuti pelatihan atau seminar - seminar kesehatan.

\section{Berdasarkan variabel pengaruh pendidikan kesehatan menggunakan booklet terhadap pemahaman pasien hipertensi di Puskesmas Kecamatan Pasar Minggu Tahun 2016}

Hasil penelitian menunjukkan ada pengaruh pendidikan kesehatan menggunakan booklet terhadap pemahaman pasien hipertensi di Puskesmas Kecamatan Pasar Minggu Tahun 2016.

Berdasarkan penelitian yang dilakukan oleh Widyasari, yang berjudul "Pengaruh Pendidikan tentang Hipertensi terhadap Perubahan Perilaku dan Pengetahuan Lansia di Desa Makamhaji Kartasura Sukoharjo" didapatkan hasil penelitian bahwa pengetahuan pasien yang tinggi dari pendidikan kesehatan tentang hipertensi sebanyak 52\%. Hal ini senada dengan hasil analisis pengaruh pengetahuan pasien hipertensi melalui pendidikan kesehatan sebelum diberi booklet diperoleh data pasien yang memiliki pengetahuan tinggi sebanyak 38 pasien $(56,72 \%)$ dan yang rendah sebanyak 29 pasien $(43,28 \%)$. Setelah diberi booklet pasien yang memilki pengetahuan tinggi sebanyak 56 pasien $(83,58 \%)$ dan yang rendah sebanyak 11 pasien $(16.42 \%){ }^{16}$

Sedangkan hasil uji kontrol terhadap 20 pasien sebelum diberikan penyuluhan penyakit hipertensi didapat 8 pasien $(40 \%)$ dengan pengetahuan tinggi dan 12 pasien (60\%) dengan pengetahuan rendah. Dan setelah diberikan penyuluhan tentang penyakit hipertensi didapat 12 pasien (60\%) dengan pendidikan tinggi dan 8 pasien (40\%) dengan pendidikan rendah. Hasil uji statistik diperoleh nilai $P$-value $=0,0001$ maka dapat disimpulkan bahwa ada pengaruh yang signifikan antara pengetahuan pasien hipertensi sebelum dan setelah penggunaan booklet perawatan pasien hipertensi di wilayah puskesmas bogor tengah.

Hipertensi atau Darah Tinggi adalah keadaan dimana seseorang mengalami peningkatan tekanan darah diatas normal atau kronis (dalam waktu yang lama). Hipertensi merupakan kelainan yang sulit diketahui oleh tubuh kita sendiri. Satu-satunya cara untuk mengetahui hipertensi adalah dengan mengukur tekanan darah kita secara teratur. ${ }^{2}$

Pengetahuan adalah merupakan hasil "tahu" dan ini terjadi setelah orang mengadakan penginderaan terhadap suatu objek tertentu. Penginderaan terhadap obyek terjadi melalui panca indra manusia yakni penglihatan, pendengaran, penciuman, rasa dan raba dengan sendiri. Pada waktu pengindraan sampai menghasilkan pengetahuan tersebut sangat dipengaruhi oleh intensitas perhatian persepsi terhadap obyek. Sebagian besar pengetahuan manusia diperoleh melalui mata dan telinga. ${ }^{6}$

Salah satu pendorong seseorang untuk merubah perilaku atau mengadopsi perilaku baru adalah pengetahuan. Pengetahuan dapat diperoleh melalui sumber informasi baik internet, surat kabar, tabloid atau majalah, radio, TV, buku, pengalaman, dan pendidikan kesehatan. Pendidikan kesehatan tentang pencegahan kekambuhan pasien isolasi sosial menjadi salah satu faktor yang menentukan keluarga untuk berperilaku dan bertindak 
dalam menghadapi pasien isolasi sosial yang pulang ke rumah. ${ }^{5}$

Pelaksanaan pendidikan kesehatan dapat diukur dari kejelasan dari tujuan yang hendak dicapai, kejelasan dari strategi pencapaian tujuan, proses analisis dan perumusan kebijakan, perencaan yang matang, penyusunan program yang tepat, sarana dan prasarana yang digunakan serta pemahaman dari target tentang pendidikan kesehatan yang diberikan. ${ }^{17}$ Sementara hasil di Rumah Sakit Duren Sawit Jakarta Timur perawat memberikan pendidikan kesehatan tanpa memperhatikan kejelasan dari tujan pendidikan kesehatan, perawat hanya memberikan pendidikan kesehatan tentang pengobatan saja, perawat tidak menggunakan media penddikan kesehatan, dan tidak melakukan evaluasi setelah memberikan pendidikan kesehatan.

Tujuan pendidikan kesehatan adalah agar orang mampu menetapkan masalah dan kebutuhan mereka sendiri, memahami apa yang mereka lakukan terhadap masalah, dengan sumber daya yang ada pada mereka ditambah dengan dukungan dari luar, meningkatkan taraf hidup sehat dan kesejahteraan masyarakat serta meningkatkan pengetahuan. ${ }^{18}$

Merupakan bagian dari keseluruhan upaya kesehatan (promotif, preventif, kuratif dan rehabilitatif) yang menitikberatkan pada upaya untuk meningkatkan perilaku hidup sehat. Pendidikan Kesehatan adalah upaya agar masyarakat berperilaku atau mengadopsikan perilaku kesehatan dengan cara persuasi, bujukan, himbauan, ajakan, memberi informasi, memberi kesadaran dan sebagainya. ${ }^{19}$

Menurut peneliti, bila pasien telah diberikan pendidikan kesehatan melalui booklet maka pengetahuan pasien tentang penyakit hipertensi pun akan meningkat. Oleh sebab itu, upaya pencegahan melalui penyuluhan oleh tenaga kesehatan dan adanya media pendidikan kesehatan sangat penting dalam menambah wawasan pasien mengenai hipertensi.

\section{Kesimpulan}

Mengacu pada hasil analisis data dan pembahasan mengenai pengaruh pendidikan kesehatan menggunakan booklet terhadap pemahaman pasien hipertensi di Puskesmas Kecamatan Pasar Minggu Tahun 2016, maka dapat dirumuskan menjadi beberapa kesimpulan: Pemahaman pasien sebelum pemberian pendidikan kesehatan menggunakan booklet sebagian besar rendah. Pemahaman pasien sesudah pemberian pendidikan kesehatan menggunakan booklet sebagian besar tinggi. Ada pengaruh pendidikan kesehatan menggunakan booklet terhadap pemahaman pasien hipertensi di Puskesmas Kecamatan Pasar Minggu Tahun 2016.

\section{Saran}

Penelitian ini dapat memberikan masukan betapa pentingnya pencegahan hipertensi melalui pendidikan kesehatan yang menggunakan media seperti booklet. Agar puskesmas dapat menjadikan program prioritas dalam rangka penurunan kasus hipertensi berulang. Dan juga sebagai masukan untuk peningkatan dan menambah media pendidikan kesehatan berupa booklet yang lebih menarik kemasannya di Puskesmas Kecamatan Pasar Minggu. Hasil penelitian ini diharapkan dapat menjadi tambahan pengetahuan bagaimana tanda dan gejala serta penyebab penyakit hipertensi dan dapat mengaplikasikan pengetahuan penyakit hipertensi agar dapat mencegah terjadinya komplikasi lebih lanjut. Diharapkan kepada institusi pendidikan agar lebih banyak memberikan materi tentang pendidikan kesehatan khususnya pada pasien hipertensi agar mahasiswa memiliki pengetahuan dan kesiapan saat bekerja di Rumah Sakit ataupun puskesmas.

\section{Daftar Pustaka}

1. Anonim. Dampak Penyakit akibat Hipertensi. Jakarta: EGC; 2010.

2. Anindya. Kebutuhan Gizi Seimbang Anak Usia Sekolah. Jakarta; 2009. Diakses pada tanggal 29 Februari 2017. http:www. rajawana.com/artikel/kesehatan/407.keb-giziseimbang-anak-usia-sekolah. html.

3. WHO. World Health Statistics 2015: World Health Organization; 2012.

4. Riskesdas. Badan Penelitian dan Pengembangan Kesehatan Kementerian RI tahun 2013. Diakses: 2013.19 Februari 2014, dari http:// www. depkes. go.id/resources/ download/ general/ Hasil \%20Riskesdas\%202013.pdf.

5. Notoatmodjo S. Promosi Kesehatan dan Ilmu Perilaku. Jakarta : Rineka Cipta; 2007.

6. Notoatmodjo S. Pendidikan Dan Perilaku Kesehatan. Jakarta: Rineka. Cipta; 2003.

7. Latipun. Psikologi Eksperimen. Malang: Universitas Muhammadiyah Malang; 2006.

8. Arikunto S. Prosedur Penelitian: Suatu Pendekatan praktek. Jakarta : P. T. Rhineka Cipta; 2002. 
9. Notoatmodjo S. Metodologi Penelitian Kesehatan. Jakarta: Rinerka Cipta; 2010.

10. Hidayat AA. Metode Penelitian Keperawatan dan teknik Analisa Data. Jakarta: Penerbit Salemba medika; 2007.

11. Ayu AY. Efektivitas Pendidikan Kesehatan Reproduksi Tentang Seks Bebas terhadap Peningkatan Pengetahuan Remaja Kelas 2 di SMK Islam Wijaya Kusuma Jakarta Selatan. (Skripsi). Jakarta. STIKIM; 2010.

12. Maulana. Konsep dan Penulisan Riset Keperawatan. Yogyakarta: Yogyakarta Graha: 2009.

13. Mahmudi. Patofisiologi. Jakarta: EGC; 2005.

14. Hendra. Buku Ajar Keperawatan MedikalBedah Edisi 8 vol.2. Jakarta: EGC; 2008.

15. Ayu, M. Hubungan Antara Kecerdasan Adversitas dengan Tingkat Stress pada Penyalah gunaan Nafza di Lembaga Pemasyarakatan Narkotika Kelas II A
Yogyakarta. (Skripsi). Yogyakarta: Fakultas Kedokteran UGM; 2014.

16. Widyasari. Pengaruh Pendidikan tentang Hipertensi terhadap Perubahan Perilaku dan Pengetahuan Lansia di Desa Makamhaji Kartasura Sukoharjo. (Skripsi). Surabaya: Universitas Kristen Petra;2010.

17. Kurniawan. Transformasi Pelayanan Publik. Yogyakarta: Pembaharuan; 2005.

18. Mubarak dan Chayatin, Ilmu Kesehatan Masyarakat Teori dan Aplikasi. Jakarta : Salemba Medika; 2009.

19. Marcelina. Model Pola Asuh orang Tua yang melakukan Perkawinan Usia Muda terhadap Anak Dalam Keluarga, (Skripsi). Malang: UIN Maliki Malang; 2013.

20. Mustofa. Hubungan pengetahuan dengan perilaku penderita hipertensi dalam pencegahan stroke. (Skripsi). Surabaya: Universitas Kristen Petra; 2013. 